\title{
HONEYCOMB LUNGS AND MALIGNANT PULMONARY ADENOMATOSIS IN SCLERODERMA
}

\author{
BY \\ HAROLD CAPLAN \\ From the Central Histological Laboratory, Whittington Hospital, London, and the \\ Department of Pathology, Highlands General Hospital, London
}

(RECEIVED FOR PUBLICATION JUNE 19, 1958)

Scleroderma was once thought to be a disease limited to the skin, but recent reports have demonstrated visceral involvement in many cases, and Goetz (1945) has suggested that a more appropriate name for the disease would be progressive systemic sclerosis. In early descriptions of generalized scleroderma (Finlay, 1891) dyspnoea and a tendency to pulmonary infections were attributed to restriction of respiratory movements produced by sclerotic changes in the skin and muscles of the chest wall. However, it seems more likely that the pulmonary symptoms are due to fibrotic changes in the lungs, and in some cases to cystic changes therein. The clinical and radiological features have been reviewed by several authors, including Hayman and Hunt (1952), who collected from the literature 27 cases of pulmonary fibrosis due to scleroderma, by Shuford, Seaman, and Goldman (1953), and by Harper (1953). Morbid anatomical studies are less complete, and it is the purpose of this paper to report on the histology of the lungs in two further cases, with special reference to the cystic changes. In these cases the epithelium lining the cysts is hyperplastic and, in one, appears to have undergone multifocal malignant change.

\section{CASE Reports}

CASE 1.--A housewife, aged 42 years, was admitted to Whittington Hospital (under the care of Dr. H. E. S. Pearson) on August 7, 1953. About 16 years previously she had developed severe pain in the fingers, with much colour change and ulceration, and then some of the distal phalanges began to drop off. After a few years her feet became affected. In 1942 four sympathectomies were performed with no benefit; if anything, her condition deteriorated. More ulcers developed on the arms and legs, and the knees, feet, and hands became stiff and drawn up In 1948 she began to have difficulty in swallowing and could only tolerate semi-solid food. Her general health deteriorated and she became bed-ridden. One month before admission she developed a chill and pain in the left chest, but improved with penicillin only to relapse. On admission she was cyanosed and orthopnoeic, cachectic (weight estimated at 5 stone, $32 \mathrm{~kg}$.) and completely devoid of subcutaneous fat. The skin was tight and thickened, with large white scars on the limbs. The elbows were ulcerated. The left leg was ulcerated to the bone and the knees immobile. The clinical diagnosis was scleroderma, pneumonia, and congestive heart failure. Despite oxygen and penicillin she deteriorated rapidly and died the next day.

Necropsy.-Necropsy was performed by Dr. A. B. Bratton. The body was that of a wasted female with tense pigmented skin, mottled on the lower limbs and adherent over bony prominences. An ulcer, 5 by 4 $\mathrm{cm}$., above the right external malleolus exposed recrotic tendon. There was dry gangrene of the right thumb and index finger, left little toe, and distal phalanges of the right fourth toe; flexion deformity of fingers and, to a lesser extent, of toes; an operation scar $14 \mathrm{~cm}$. long just to the right of the umbilicus, and a curved scar $16 \mathrm{~cm}$. long on the back, with maximum convexity rising to just below the level of the seventh cervical spine.

The pericardium contained an effusion of $2 \mathrm{oz}$. $(60 \mathrm{ml}$.) and showed a patchy opacity of its visceral layer, with tough adhesions along the upper part of the margo obtusa. The heart weighed $13 \mathrm{oz}$. (37 g.) and showed hypertrophy of the myocardium and dilatation of the left ventricle; the myocardium was pale but not obviously fibrotic, and the valves normal. There was considerable atheroma of the coronary arteries and aorta. Both pleurae contained effusions of about $20 \mathrm{oz}$. (540 ml.) with multiple scattered fibrous adhesions. The lungs were generally congested and oedematous; the lower lobe of the right lung was firm but aerated.

The lower oesophagus was dilated up to $6 \mathrm{~cm}$. diameter, the dilatation extending down to $4 \mathrm{~cm}$. from the stomach. There was mucous catarrh of the stomach; slight narrowing of the lower one-half of the colon; and fibrosis of the appendix. The atrophied liver, the relatively large spleen, and the pancreas were congested. The atrophied kidneys 


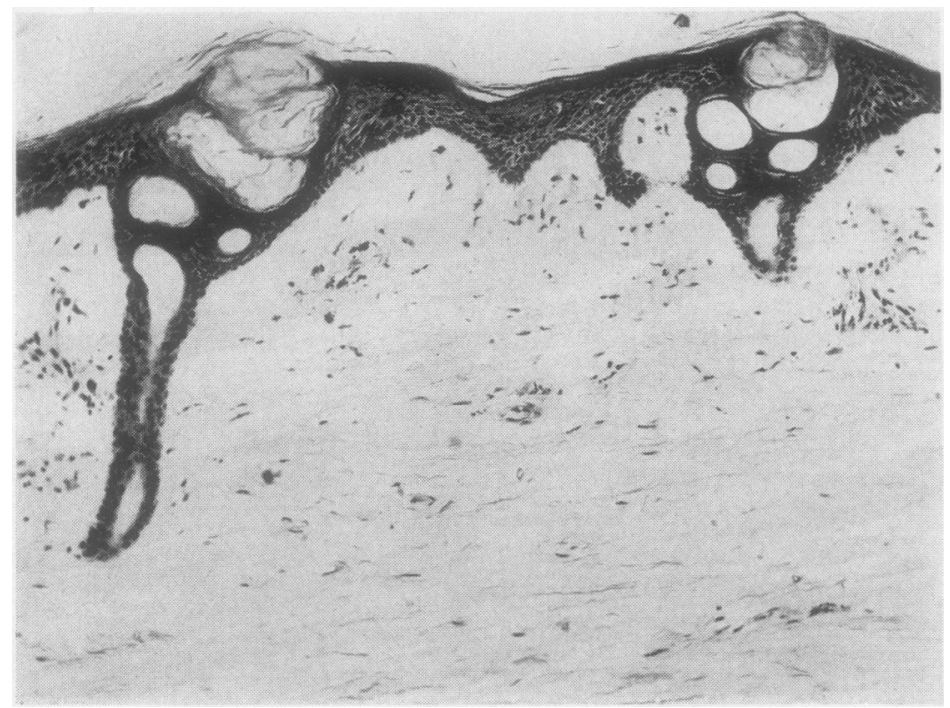

FIG, 1-Case 1. Sclerodermatous changes in skin from a finger. Haematoxylin and eosin $\times 90$.

Fig. 2.-Case 1. Lower lobe of the right lung showing cysts, some without definite epithelial lining. some lined by heapedup cuboidal epitheliur. Haematoxylin and eosin $\checkmark 90$.

Fig. 3.-Case 1. Lower lobe of the right lung showing cuboidal epithelium apparently invading fibrous lung stroma. Haematoxylin and eosin $\times 90$.

FIG. 1

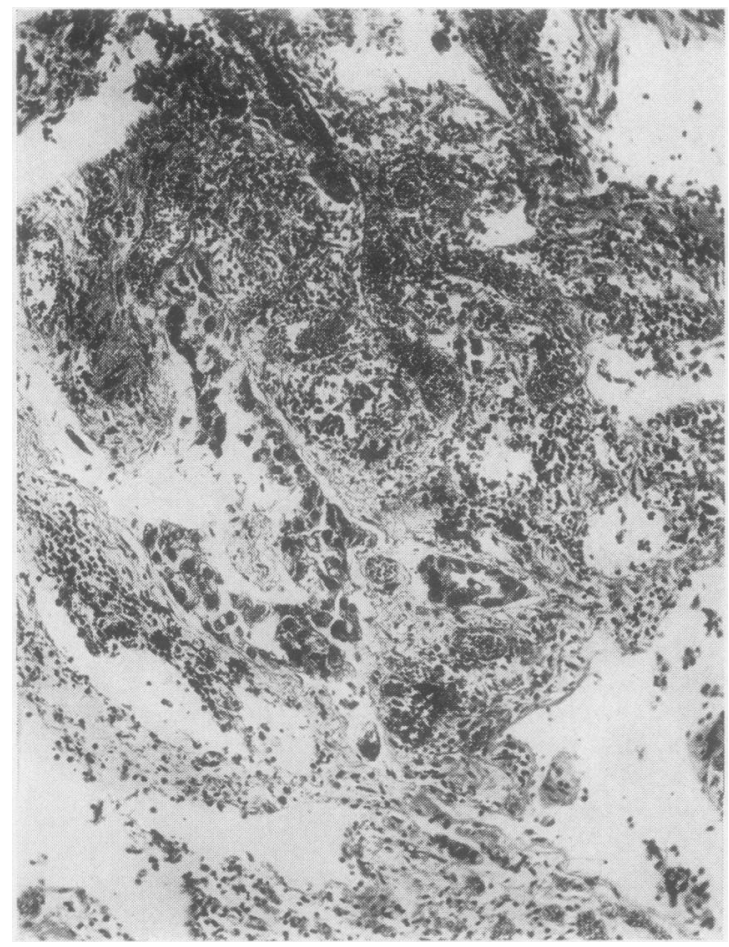

F!G. 2

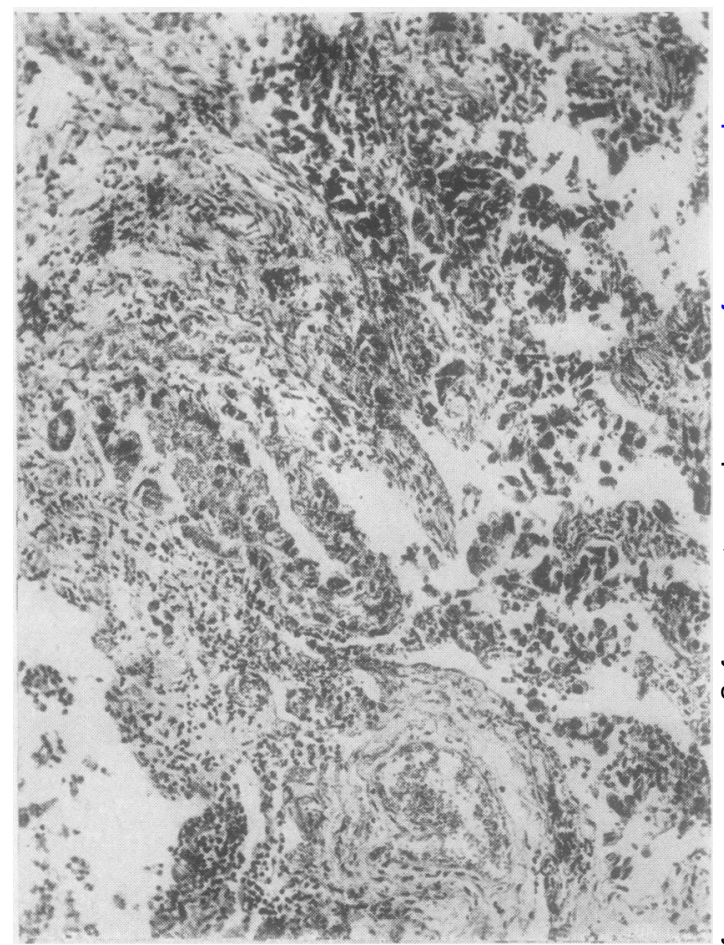

Fig. 3 
were mottled, with haemorrhages in the cortex up to 1.0 by $0.4 \mathrm{~cm}$. The suprarenals were normal.

The uterus and the ovaries were atrophied and there were fibrous adhesions at the ends of both Fallopian tubes, with a simple fimbrial cyst $2 \mathrm{~cm}$. in diameter on the left.

The brain was oedematous. The middle ears were clean.

Histological sections of the skin of the neck, elbow, finger, abdomen, and leg show typical scleroderma changes. The epidermis shows atrophy and pigmentation. In the dermis and subcutis there are hypertrophy and hyalinization of collagen, sometimes with oedema, atrophy, and disruption of elastic fibres, atrophy of hair follicles, and focal chronic inflammation, mainly around sweat glands (Fig. 1).

Sections of the lower lobe of the right lung show a system of thin-walled cysts about 1-2 mm. in diameter, mainly without definite lining epithelium, but some are partially lined by regular cuboidal or ciliated columnar epithelium up to four cells thick (Fig. 2). One focus of this epithelium merges gradually with tubular masses of polygonal cells which appear to be invading anthracotic, fibrous stroma-" scar carcinoma" (Fig. 3). Much fibrous tissue and smooth muscle are present in the walls of these cysts and there is also plentiful elastic tissue in irregular clumps and strands. Many of the cysts are filled with mucopurulent exudate. A section from the lower lobe of the left lung shows congestion, chronic bronchitis, slight emphysema, and fibrosis. There is atrophy of muscle fibres of the rectus abdominis with extensive loss of striation and several foci of proliferation of sarcolemmal nuclei. There is dense hyaline fibrosis of mucosa and submucosa, and chronic inflammatory cell infiltration of mucosa of the base of the tongue. The mucosa of the lower end of the oesophagus is ulcerated and there is much fibrosis of submucosa and muscles. The stomach and small intestines show only post-mortem changes. There is a slight focal fibrosis of the muscularis of the colon with surrounding chronic inflammation, and endarteritis of a vessel in the overlying serosa ; this shows much reduplication and fragmentation of internal elastic lamella. Sections of the kidney show ischaemic fibrosis, multiple infarcts, focal endarteritis, slight thickenings of basement membrane of glomeruli, and slight patchy, fatty changes in tubules. There is cloudy swelling, oedema, and a trace of fatty change in the myocardium of the left ventricle. The liver shows centrilobular brown atrophy and early heart failure changes. The spleen is congested with slight fibrosis of reticulum. The suprarenals are congested and there is a simple fimbrial cyst of the left Fallopian tube.

CASE 2.-A housewife, aged 60 years, was admitted to Whittington Hospital on May 2, 1954 (under the care of Dr. M. G. Ashby), with a history of five weeks of increasing breathlessness. She had had " arthritis" for about 30 years. On examination she was found to be very ill and frail (temperature $99^{\circ} \mathrm{F}$., pulse 110 per minute). The skin of the face and hands was white, tight, and stiff, with a macular rash on the face. There was a massive left pleural effusion which on aspiration was found to be very heavily blood-stained. Malignant cells were seen in the fluid (Dr. S. Robinson). The patient went steadily downhill and died on May 19, 1954. The clinical diagnosis was malignant pleurisy, carcinoma of lung, and scleroderma.

Necropsy.-Necropsy was performed by Dr. A. B. Bratton.

The body was that of a well-nourished, welldeveloped woman. The skin was smooth and adherent with pinkish-red mottling of cheeks, nose, and, to a lesser extent, on the dorsum of the hands and fingers.

There was organizing or fibrinous inflammation of the pericardium on the left side of the heart with one fibrous adhesion, with cloudy swelling of the myocardium, and slight atheroma of the coronary arteries and aorta.

The lower lobe of the left lung was collapsed and there was a consolidated area suggesting organizing pneumonia, 2.0 by $1.0 \mathrm{~cm}$., at the lower border of the left upper lobe. There was an area of spongy fibrosis at the base of the right lung. There were organizing fibro-fibrinous adhesions of the left pleura, with a deeply blood-stained effusion of approximately 2 pints $(1,080 \mathrm{ml}$.), and slight thickening of the left parietal pleura and adherent diaphragm.

There was slight fibrosis of the thyroid gland. The liver and the kidneys showed cloudy swelling and slight congestion. Three mixed calculi, each about $0.8 \mathrm{~cm}$. diameter, were present in the gall bladder. The spleen was congested. The suprarenals and the stomach were normal. A polypous lipoma, 3.5 by 1.5 by $1.0 \mathrm{~cm}$., was found in the upper jejunum, and about 25 diverticula up to $0.5 \mathrm{~cm}$. diameter in the pelvic colon. The atrophied uterus contained simple fibroids up to $2.0 \mathrm{~cm}$. diameter, and the right ovary was replaced by a slightly papillary unilocular cyst 4.5 by 4.5 by $3.5 \mathrm{~cm}$. The brain was normal, and the middle ears clean.

Histological sections of the skin of the hand show changes characteristic of scleroderma. The epidermis shows hyperkeratosis and atrophy with flattening of the rete pegs. There is coarse reticular fibrosis of the subcutis, and diffuse hyaline fibrosis of the dermis with focal acute inflammatory infiltration. The walls of some of the small arteries in the subcutis have undergone fibrinoid necrosis and fibrin thrombi are present in some of the intradermal arterioles (Fig. 4).

Section of the base of the right lung shows a system of cysts and tubules of varying shape and size, usually about 1-2 mm. diameter. Most of the cysts are lined by a single layer of regular columnar epithelium, which in some areas is clearly ciliated; some parts of the cyst walls are lined by flattened or cuboidal epithelium occasionally showing squamous metaplasia; other parts are devoid of epithelial 


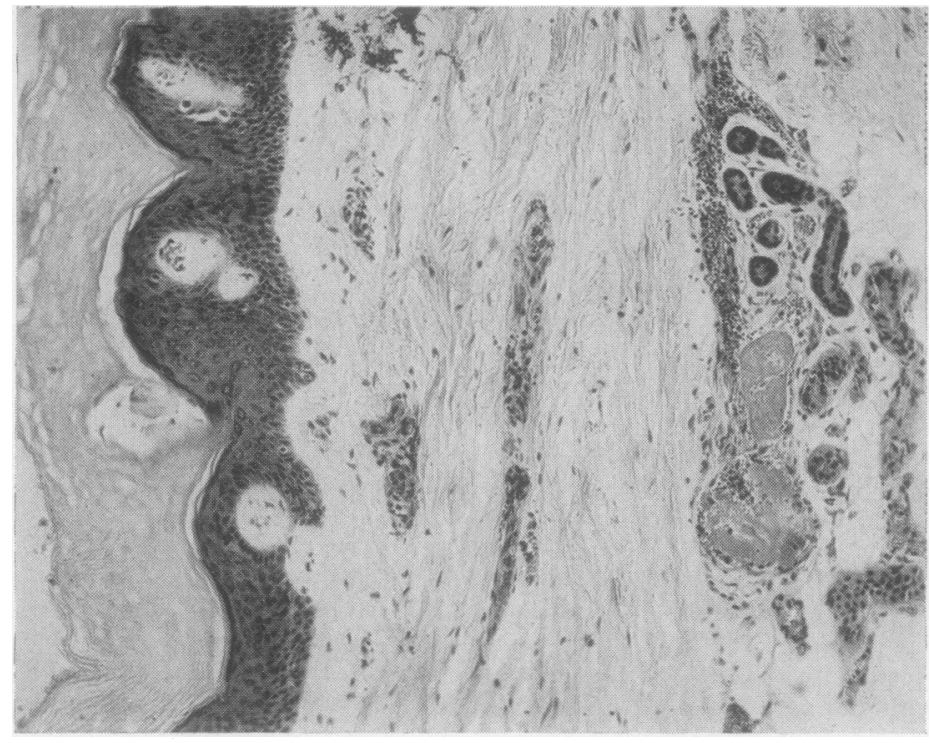

FIG 4
FIG. 4.-Case 2. Sclerodermatous changes in skin from the dorsum of a hand ; fibrin thrombi in intradermal arteriole. Haematoxylin and eosin $\therefore 90$.

FIG. 5.-Case 2. Lower lobe of the right lung showing cysts lined by regular ciliated columnar epithelium; arrow indicates area of fibrinoid necrosis. Haematoxylin and eosin $\times 90$.

FIg. 6.-Case 2. Lower lobe of the right lung showing elastic tissue in the walls of cysts. Weigert's elastin 90 .

FIG. 7.-Case 2. Lower lobe of the lefi lung showing heaped-up epithelium in cysts merging with cuboidal and polygonalcelled carcinoma. Haematoxylin and eosin $\times 90$.

FIG. 8.-Case 2. Upper lobe of the left lung showing cuboidal and polygonal-celled carcinoma in partly cystic, fibro-elastic lung; much carbon pigment present. Haematoxylin and eosin 90.

FIG. 9.-Case 2. Secondary carcinoma in visceral pleura and subpleural lymph vessels. Haematoxylin and eosin $<90$.

FIG. 10.-Case 2. Secondary carcinoma in the diaphragm. Haematoxylin and eosin $\times 90$.

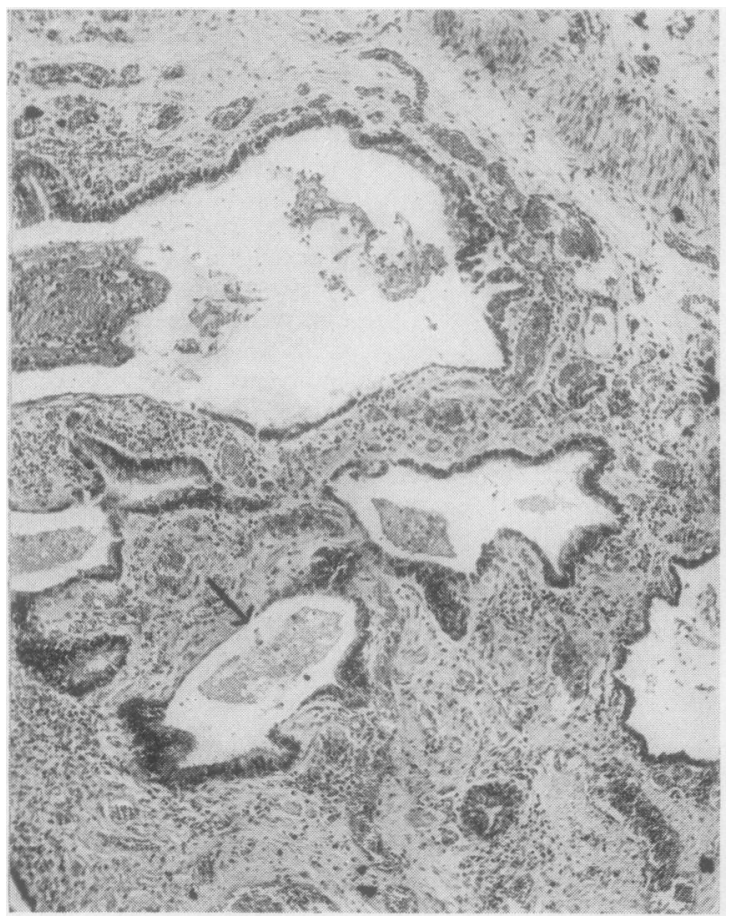

FIG. 5

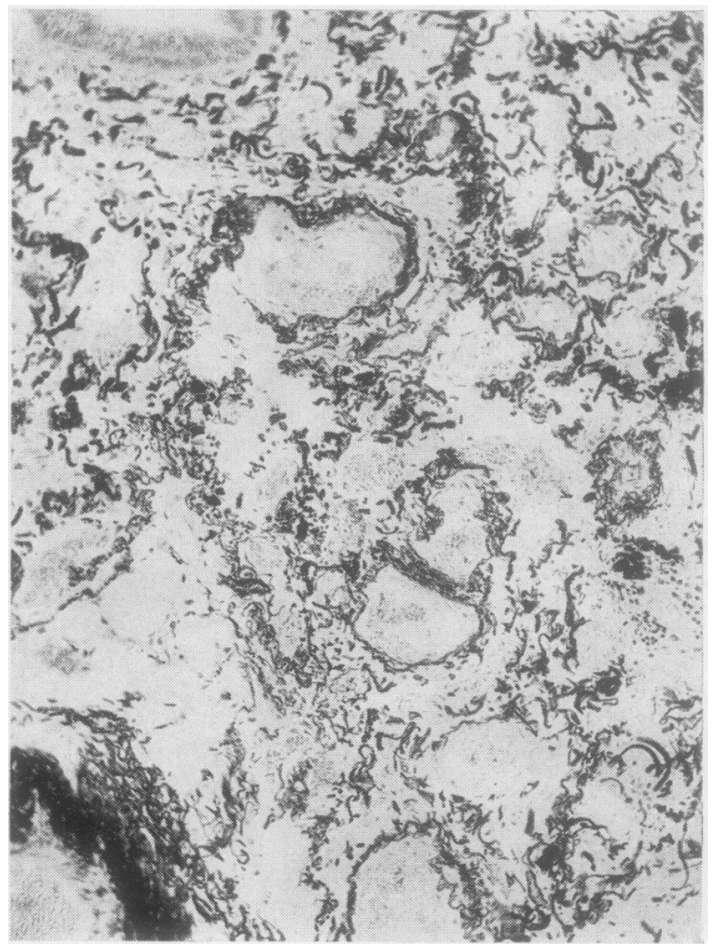

FIG 6 


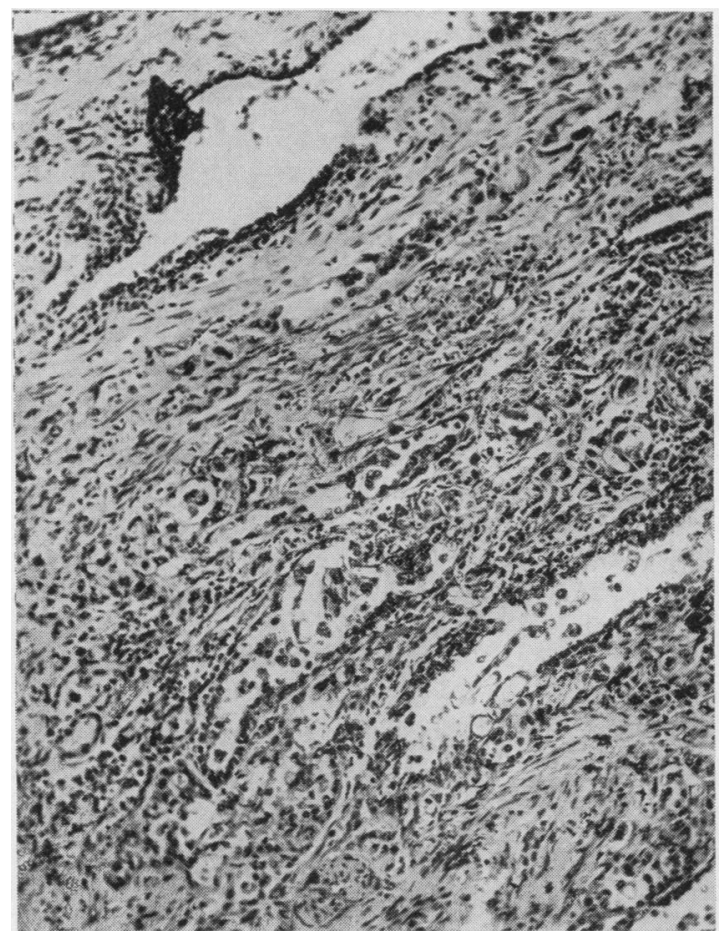

FiG. 7

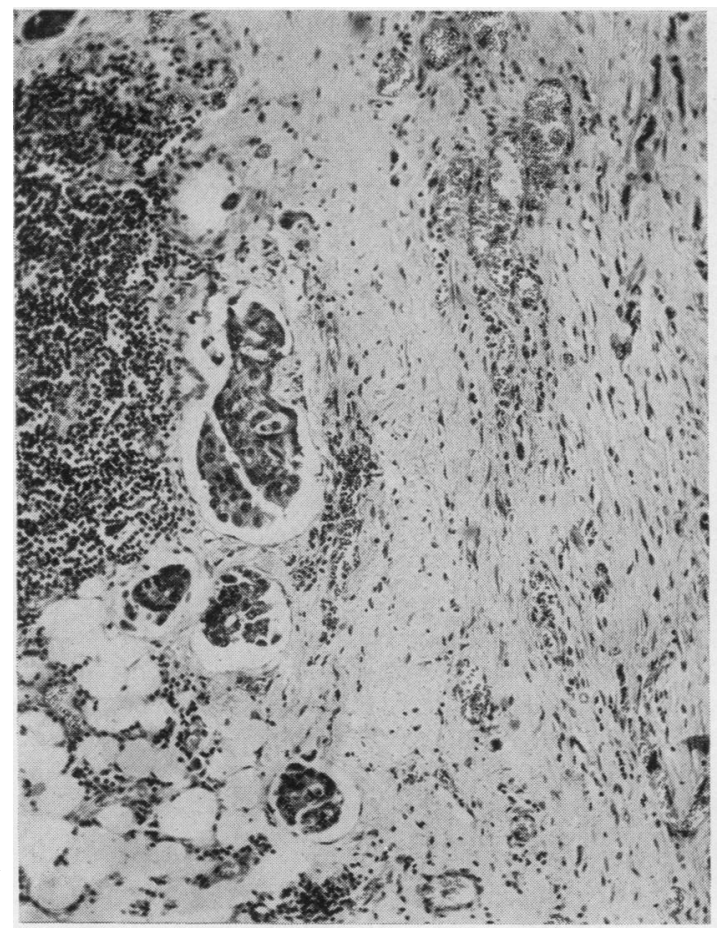

9.

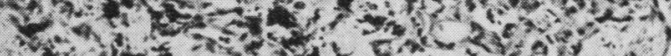

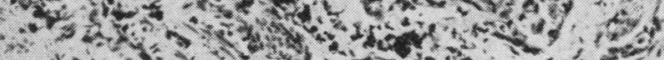

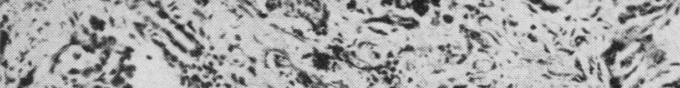

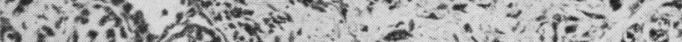
?.619.9.

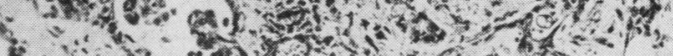

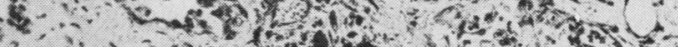

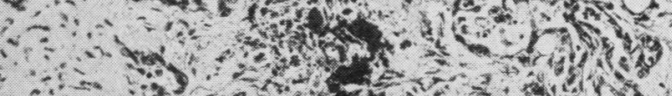

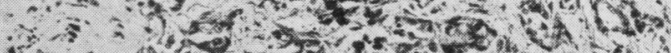

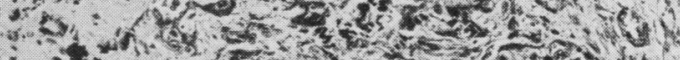

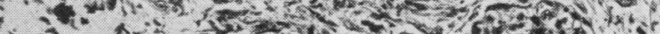

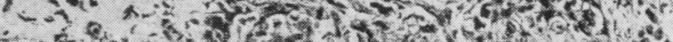

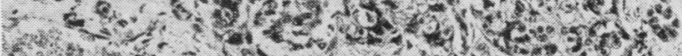

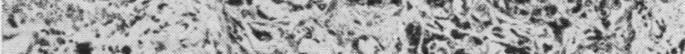

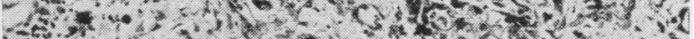

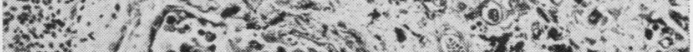

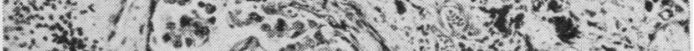

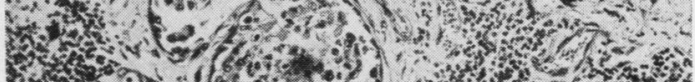
3.

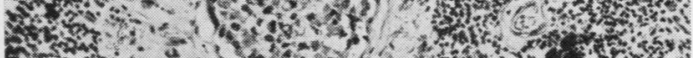
S. FIG 8

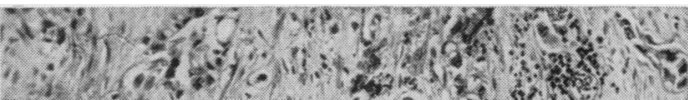

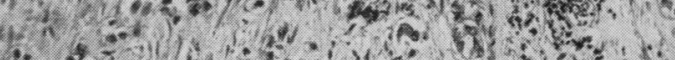

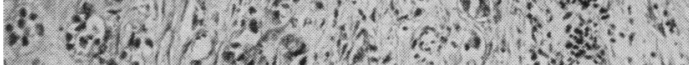

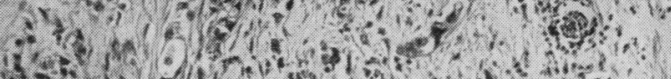
"20.

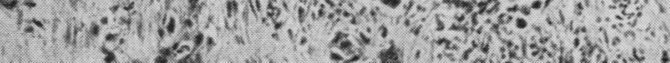

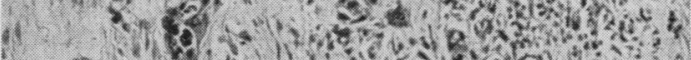

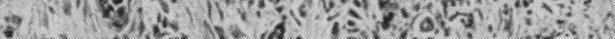

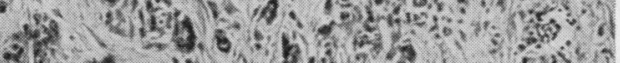
26.

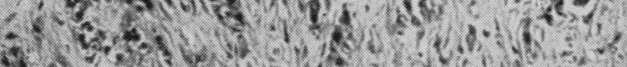

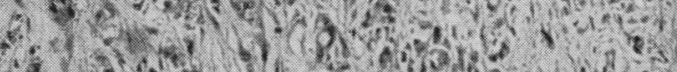

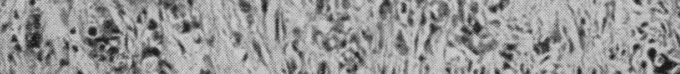

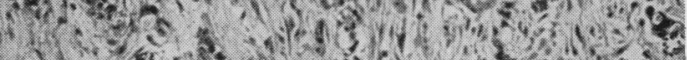

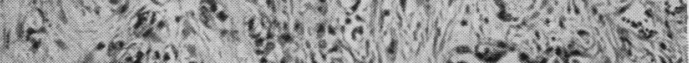

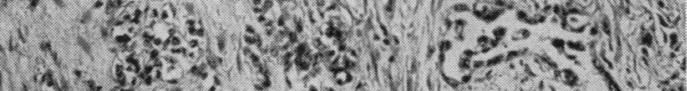

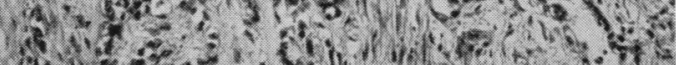

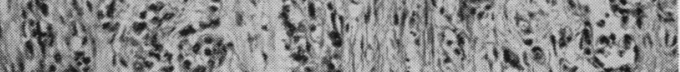
Fig. 10 
lining. Some of the cysts are lined by more than one type of epithelium. There are occasional foci of fibrinoid necrosis in the cyst walls (Fig. 5). Most of the cysts are empty; some contain mucus and carbon-laden macrophages. Giant cells are not present. The interstitial tissue between the cysts is well vascularized and fibrous, with diffuse and focal infiltration with chronic inflammatory cells including lymphocytes, plasma cells, and carbon-laden macrophages. Extracellular carbonaceous pigment is scattered in the fibrous tissue, but the amount is no greater than that usually found in town-dwellers. Smooth muscle is conspicuous, partly as regular bundles around the cysts and partly as bundles or isolated fibres completely irregularly disposed in fibrous tissue. Elastic tissue is plentiful (Fig. 6), either as single strands, small knots, or as dense tangled masses and bands. In some areas the elastic pattern resembles that of expanded lung, in others that of collapsed lung. The larger arteries and arterioles are normal, but some of the small arteries show moderate intimal hyperplasia. There is overlying chronic pleurisy.

Similar cystic changes are present in the sections of the collapsed lower lobe of the left lung with the addition of an area of heaping-up of columnar and cuboidal epithelium of the cyst lining. This area is immediately adjacent to and blends with an area of tubular and trabecular, cuboidal, and polygonalcelled carcinoma in anthracotic fibro-elastic lung tissue (Fig. 7).

The section of the upper lobe of the left lung shows tubular and trabecular, cuboidal and polygonal-celled carcinoma in partly cystic, fibroelastic lung (Fig. 8). There is much carbon pigmentation of this fibrotic area. The overlying pleura shows chronic fibrino-fibrous inflammation and is invaded by groups of carcinoma cells (Fig. 9). Secondary carcinoma is also present in fibrotic parietal pleura and adherent diaphragm (Fig. 10).

Section of the oesophagus shows focal thickening of squamous epithelium alternating with small erosions. There is much subepidermal chronic inflammatory celled infiltration, including small round cells, plasma cells, and eosinophils. Atrophy of the muscle is not a feature. There are atrophy of the mucosa and focal chronic inflammation at the cardiac end of the stomach and slight chronic inflammation in the jejunum, which also includes a polypous, submucous lipoma. There is slight mucous catarrh and chronic inflammation of the colon. The liver shows cloudy swelling and centrilobular congestion with moderate increase in subcapsular and periportal fibrous tissue with proliferation of the bile ducts. The spleen is congested. The kidneys show cloudy swelling and slight congestion and ischaemic fibrosis. There is no fibrinoid necrosis of arterioles.

\section{Discussion}

There can be little doubt of the validity of the diagnosis of scleroderma in both these cases, the histological appearances in the skin being characteristic. The possibility must be considered that the pulmonary changes in Case 2 (where there is a long history of "arthritis") are of rheumatoid origin. Since Ellman and Ball (1948) described a patchy fibrosing pneumonitis and alveolar fibrosis in patients with rheumatoid arthritis, over 50 such cases have been reported (Edge and Rickards, 1957). If the lung lesion is characterized by rheumatoid necrobiosis its interpretation is in no doubt, for the histological appearances are specific to rheumatoid disease. In the absence of necrobiotic foci the diagnosis of rheumatoid lung disease is, at best, presumptive and there is little basis for such a diagnosis here.

Cystic changes have been described in lungs in scleroderma by Getzowa (1945), Church and Ellis (1950), Heppleston (1956), two cases each, and by Spain and Thomas (1950), Aronson and Wallerstein (1950), Hayman and Hunt (1952), Evans and Parker (1954), and Israel and Harley (1956), one case each. Of these 11 cases eight were subjected to necropsy, so that, including my two cases, there are now histological reports of 10 cases which all show similar pathological features. The cysts in all the cases were situated in the periphery of the lung, communicated with bronchi, had a fairly thick fibrous wall including variable amounts of elastic tissue, and were partially or completely lined by cuboidal or columnar epithelium which was sometimes ciliated.

These changes show no essential difference from those found in honeycomb lung (Cunningham and Parkinson, 1950; Heppleston. 1956), and there can be no reasonable doubt that scleroderma should be included in the group of conditions in which honeycomb lungs occur. It might be argued that the changes are the result of infection in congenital cystic disease existing coincidentally with scleroderma. This seems unlikely for two reasons. First, the cysts in congenital disease are completely isolated from the bronchial tree (Norris and Tyson, 1947), which is in manifest contrast to the findings in scleroderma ; and, second, there are several reports (including Goetz, 1945; Hayman and Hunt, 1952; and Shuford and others, 1953) of pulmonary fibrosis in scleroderma without cysts. This suggests that the fibrosis is the primary change and the cyst formation is secondary, possibly as a result of bronchiolectasis compensatory to obliteration by the fibrosis of other bronchioles and their subdivisions. Thus the pulmonary fibrosis of scleroderma is similar 
to other pulmonary fibroses or granulomata, such as are found in association with sarcoidosis, berylliosis, or tuberculous bronchopneumonia (Heppleston, 1956), in being the antecedent of honeycomb lung.

EPITHElal Hyperplasia.-Epithelial proliferation may occur occasionally in sclerodermatous lungs. Goetz (1945) described "gland-like outgrowths of alveolar epithelium " in the lungs of a 42-year-old woman who died of progressive systemic sclerosis, and Getzowa (1945) described "adenoma-like" lesions in areas of compact fibrous tissue around the bronchi in cases of scleroderma. Further, in six cases of honeycomb lung reported by Heppleston (1956) the degree of proliferation was excessive, being greater than necessary merely to line the cysts and resulted in a thick stratified or papillary epithelium for which the term adenomatosis (with its implication of potential neoplasia) appeared justified.

In Case 1 here reported the hyperplastic epithelium can be seen to merge gradually with tubular masses of polygonal cells in fibrous lung tissue. Whilst the impression is that of neoplasia, in the absence of unequivocal evidence of invasion or metastasis one cannot be certain, and the case must be considered as one of pulmonary adenomatosis showing premalignant (possibly early malignant) changes. However, in Case 2 there can be no doubt as to the true carcinomatous nature of the lesion. The lung was frankly invaded by cuboidal and polygonal celled carcinoma which was continuous with the hyperplastic epithelium of the cyst lining, and there were metastases in the visceral pleura of the upper lobe of the left lung and in the diaphragm. Further, carcinoma cells were present in the pleural fluid during life.

Areas of epithelial hyperplasia in terminal bronchioles and alveoli are well recognized. Pagel (1926) reviewed the earlier references and described unusual proliferations of atypical and heterotopic epithelium in bronchiectasis. Whitwell (1955) examined 2,300 surgical specimens of lung and 1,400 necropsy specimens and found nodules of epithelial hyperplasia which he called "tumourlets" in 24 cases ( 22 surgical). $\mathrm{He}$ could find no extension to lymph nodes in the 15 specimens which could be examined for this. In a study of 102 surgically resected specimens of bronchiectatic lung, Cunningham, Nassau, and Walter (1958) found this type of lesion in 20 cases in none of which were any lymph node deposits found. However, Spain and Parsonnet (1951) reported metastases in the regional lymph nodes in a case of "bronchiolargenic" tumour of multifocal origin, in some sections of which the cells tended to resemble undifferentiated squamous cells and, in other areas, oat-cells.

It would seem valid to differentiate between "tumourlets" and pulmonary (bronchiolar) adenomatosis. Both appear to arise in association with lung damage, but " tumourlets" are small, round, and oat-celled neoplasms which are said rarely to undergo malignant change (Cunningham and others, 1958), while the tumours of pulmonary adenomatosis are derived from columnar cells, with or without cilia, mucus-secreting cells, or low flattened cubical epithelial cells, or they may be multilayered with a resemblance to squamous epithelium (Spencer and Raeburn, 1956). Further, malignant change not infrequently supervenes on pulmonary adenomatosis (Smith, 1957) and may occur in association with fibrous apical scars (James and Pagel, 1944), bronchial scars resulting from tuberculous ulceration (Schwartz, 1950), bronchiectasis (Stewart and Allison, 1943; Cureton and Hill, 1955; Beaver and Shapiro, 1956), pulmonary fibrosis (Raeburn and Spencer, 1953) and, as shown by these two cases, scleroderma.

Spain (1957) has reviewed a series of 12 cases of "terminal bronchiolar carcinoma" associated with various degrees of interstitial inflammation and fibrosis of the lung. In one of these cases there is a history of exposure to beryllium; in one case there was clinical and pathological evidence of the inhalation of lipid material, and in two there was evidence of healed and obsolete tuberculosis with widespread fibrosis. This author considers that the tumour formation is probably secondary to the inflammation and fibrosis, and that an analogy might be made to the situation in the liver when hepatocellular carcinoma develops on a background of the regenerative hyperplasia of liver cells that occurs in hepatic cirrhosis irrespective of the aetiology of the cirrhosis.

The precise mode of pathogenesis of the hyperplastic epithelium is obscure. Bell (1943) considered that the epithelial metaplasia results from a "loss of respiratory function due to the thickening of the inter-alveolar septa or filling of the alveoli with foreign material." King (1954) pointed out that the epithelial proliferations occur immediately around areas of relative fixation in the lung. Spencer and Raeburn (1956) produced evidence to show that both benign and malignant pulmonary adenomatosis originate as a bronchiolar reaction to lung damage and fibrosis. 
Swan (1949) was of a similar opinion and further suggested that epithelialization of the fibrosed alveoli is a direct consequence of lung damage, and the mucus production by the newly formed epithelium is analogous to that found in catarrhal inflammation of mucous membranes. Whether or not this is so is a question which cannot be answered at this time, but the two cases here reported are consistent with the hypothesis that the hyperplastic epithelial changes are in some way related to impaired respiratory function associated with increased pulmonary fibrosis.

\section{SUMMARY}

Two cases of scleroderma associated with cystic changes in the lungs and pulmonary adenomatosis are described. In Case 1 the adenomatosis was possibly malignant, in Case 2 it was unequivocally so with metastases to pleura and diaphragm.

The appearances of cystic fibrosis of the lungs found in association with scleroderma are discussed. It is considered that these changes show no essential difference from those found in honeycomb lung and that the pulmonary fibrosis of scleroderma is similar to other pulmonary fibrosis or granulomata in being the antecedent of honeycomb lung.

The relation of "tumourlets" and pulmonary adenomatosis to carcinoma and the pathogenesis of hyperplastic respiratory epithelium are discussed. The hypothesis is put forward that the hyperplastic epithelial changes are in some way related to impaired respiratory function associated with increased pulmonary fibrosis.

I wish to thank Dr. A. B. Bratton for the necropsy reports and much valued discussion, criticism, and encouragement ; Dr. S. Robinson for ready help and advice; Drs. W. Pagel and P. M. Peters for their opinions; Mr. G. W. Moore for the photomicrographs, and Miss Cynthia Kearns for secretarial assistance.

\section{REFERENCES}

Aronson, S. M., and Wallerstein, L. (1950), N.Y. St. J. Med., 50 2723.

Beaver, D. L., and Shapiro, J. L. (1956). Amer. J. Med., 21, 879. Bell, E. T. (1943). Amer. J. Path., 19,901.

Church, R. E., and Ellis, A. R. P. (1950). Lancet, 1, 392

Cunningham, G. J., and Parkinson, T. (1950). Thorax, 5, 43.

Nassau, E., and Walter, J. B. (1958). Ibid., 13, 64

Cureton, R. J. R., and Hill, I. M. (1955). Ibid., 10, 131.

Edge, J. R., and Rickards, A. G. (1957). Ibid., 12, 352.

Ellman, P., and Ball, R. E. (1948). Brit. med. J., 2, 816.

Evans, M., and Parker, R. A. (1954). Thorax, 8, 154.

Finlay, - (1891). Middlesex Hospital Reports, p. 29.

Getzowa, S. (1945). Arch. Path. (Chicago), 40, 99.

Goetz, R. H. (1945). Clin. Proc., 4, 337.

Harper, R. A. K. (1953). Proc. roy. Soc. Med., 46, 512.

Hayman, L. D., and Hunt, R. E. (1952). Dis. Chest, 21, 691.

Heppleston, A. G. (1956). Thorax, 11, 77.

Israel, M. S., and Harley, B. J. S. (1956). Ibid., 11, 113.

James, I., and Pagel, W. (1944). Brit. J. Surg., 32, 85.

King, L. S. (1954). A.M.A. Arch. Path., 58, 59.

Norris, R. F., and Tyson, R. M. (1947). Amer. J. Path., 23, 1075

Pagel, W. (1926). Virchows Arch. path. Anat., 262, 583.

Raeburn, C., and Spencer, H. (1953). Thorax, 8, 1.

Schwartz, P. (1950). Beitr. klin. Tuberk., 103, 192.

Schwartz, w. (19). Seaman, w. B. Arch. intern. Med., 92, 85 .

Smith, K. V. (1957). J. Path. Bact., 73, 167.

Spain, D. M. (1957). Amer. Rev. Tuberc., 76, 559.

and Parsonnet, V. (1951). Cancer, 4,277.

- and Thomas, A. G. (1950). Ann. intern. Med., 32, 152.

Spencer, H., and Raeburn, C. (1956). J. Path. Bact., 71, 145.

Stewart, M. J., and Allison, P. R. (1943). Ibid., 55, 105.

Swan, L. L. (1949). Arch. Path. (Chicago), 47, 517.

Whitwell, F. (1955). J. Path. Bact., 70, 529. 